similar explanation might apply to the cases of optic neuritis from persistent vomiting after operation, quoted by Wagener and Weir. In this connection also it will be remembered that in some cases of retrobulbar neuritis from tobacco there is a history of chronic alcoholism with gastro-enteritis.

In most of the above mentioned conditions there is either persistent vomiting or a state of the gastro-intestinal tract which would favour the loss or destruction of the ingested vitamins. Which brings us back to the suggestion that Wernicke's syndrome may result from a deficiency of vitamin $B_{1}$, combined with some form of toxin. The rapid and striking restoration of vision under vitamin $\mathrm{B}_{1}$ treatment in $\mathrm{Mr}$. Black's and other cases, strongly emphasises the importance of the vitamin factor in hyperemesis gravidarum, and it appears that this form of treatment may well revolutionise the prognosis in these cases.

I was particularly interested that Mr. Black was impressed with the unusual picture of the retinal haemorrhages without exudates, which I too was inclined to think characteristic of the fundus in advanced cases of hyperemesis gravidarum.

Incidentally, I might mention that Mrs. B., the patient described in my paper, who made a complete recovery after total blindness, was a victim of the air raid of March 14, in which she received severe injuries to the face and both eyes. She came under the care of my friend, Dr. W. J. B. Riddell, who found in her right eye intra-ocular haemorrhages, retinitis proliferans and traumatic cataract, while the left eye had a penetrating wound with prolapse of the iris. The right eye sees no more than "hand movements"; but the left eye, for the second time within twelve months, has recovered normal vision.

Yours faithfully,

A. J. Ballantyne.

11. Sandyford Place,

GlasGow, C.3

September 9, 1941.

\title{
OBITUARY
}

\section{JOHN JAMESON EVANS}

THE death occurred on August 13, 1941, at Froneithyn, Aberdovey, of John Jameson Evans of Edgbaston, Birmingham. Born in 1871, his early education was at St. David's College School, Lampeter, and Queen Elizabeth's Grammar School, Carmarthen. When he 
- decided on medicine as a career he went to Edinburgh University and graduated in 1892 M.B, C.M. with honours. In 1899 he became F.R.C.S. England, and in 1903 M.D. Birmingham.

After qualification Mr. Jameson Evans spent three years at the Carmarthen County Infirmary and then went to Birmingham where, after three years, he was appointed Honorary Ophthalmic Surgeon to the Birmingham \& Midland Eye Hospital and continued to serve in that capacity till 1934 when he became Consulting Surgeon. In addition he was Consulting Ophthalmic Surgeon to Birmingham General Dispensary and Ophthalmic Surgeon to Hallam Hospital, West Bromwich, for many years : he was also Honorary Ophthalmic Surgeon to the Birmingham Royal Institution for the Blind. On different occasions he was President of the Midland Medical Society; of the Birmingham branch of the British Medical Association, and of the Midland Ophthalmological Society; and VicePresident of the ophthalmic section of the British Medical Association, and of the Ophthalmological Society of the United Kingdom. He served on the council of the Oxford Ophthalmological Congress, of which he was a foundation member, for nineteen years, and held the position of Lecturer in Ophthalmology in the University of Birmingham for twenty-five years. He was Middlemore Lecturer on several occasions and his numerous publications covered a wide range of ophthalmic and related subjects.

Mr. Jameson Evans leaves a widow, the second daughter of the late Principal Edwards, of Aberystwyth, and two sons, both of whom are engaged in medical practice.

\section{Mr. Harrison Butler writes-}

I first met Jameson Evans in 1907 when I started work in Coventry. That was the beginning of an association which ended only with his death. When I joined the Honorary Staff of the Birmingham Eye Hospital in 1913 it was my good fortune to sit on the same days as Jameson Evans, and for eighteen years we worked at neighbouring desks, becoming intimately acquainted with each other's cases, and rendering mutual help. The longer I worked with Evans the more I appreciated his worth both as a man and as an ophthalmologist. During this long period, which included the arduous times of the last war, we never had the slightest disagreement, and his sunny nature created a genial atmosphere that made our mornings at the hospital happier both for the staff and the patients. His treatment of his hospital cases was an example to all. Never once did I hear him say an unkind or even rough word to any of them, always there was a kind word and encouraging smile, or a pleasant witticism. Professionally, to work with him was an 


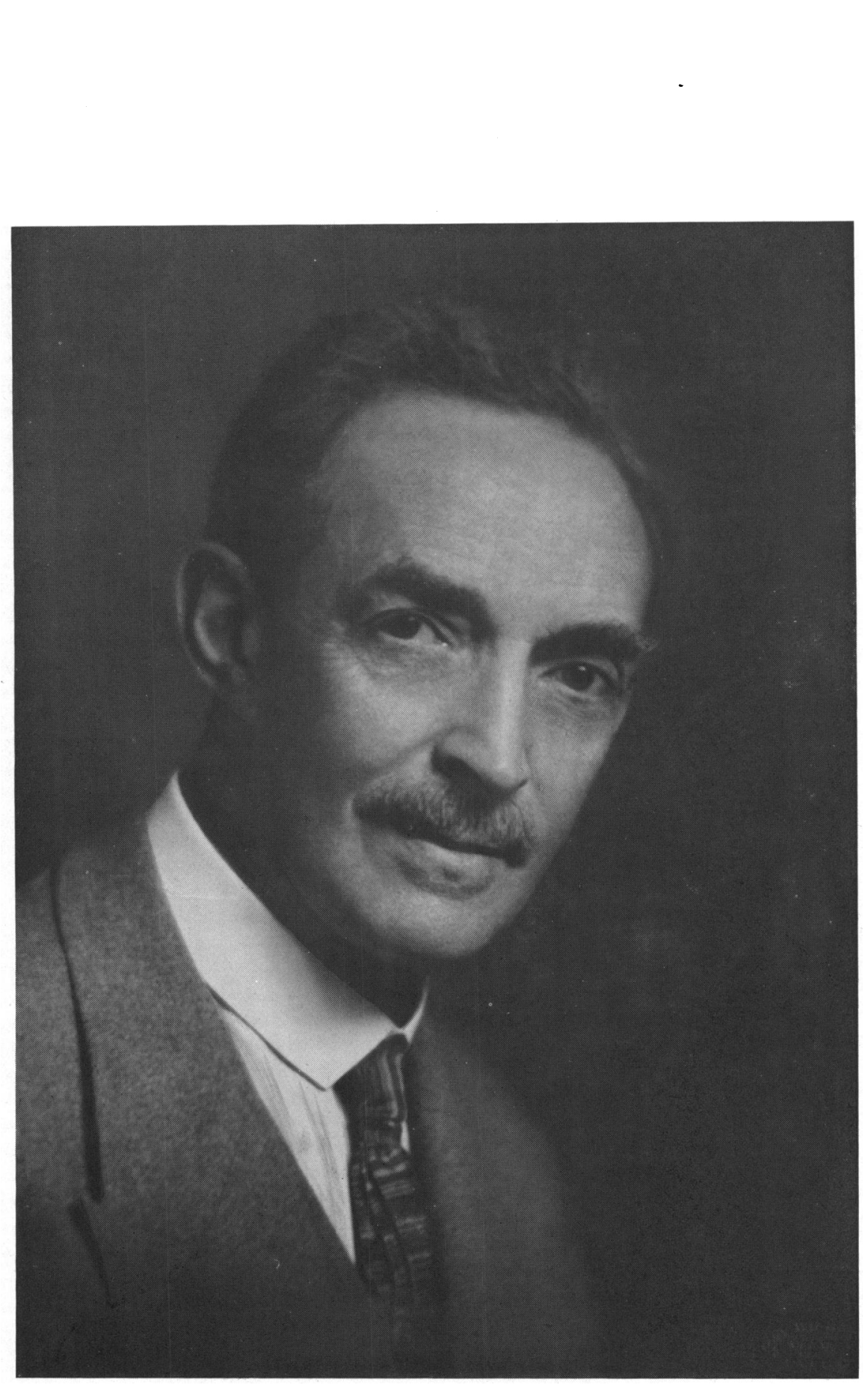

$\overrightarrow{0}$ 응 을. 흘윙 응

ฉั 
inspiration. His knowledge of ocular disease was far reaching and his opinion on a case almost final. His ophthalmoscopy was superb, and pathology to him was a hobby. For many years he had undertaken all the pathological work of the hospital, and I am sure that he loved this side of the work of the hospital above all. For many years he held the office of Reader in Ophthalmology to the University of Birmingham, following Priestley Smith, who was Professor of Ophthalmology. He brought out a useful little brochure embodying the essential features of his teaching.

Jameson Evans had a large circle of friends, and his intimates in the profession called him "Sunny Jim," an epithet which exactly described his nature. All of us feel that we have lost for the time being a good friend, a valuable mentor, and an outstanding example for all to imitate.

Jameson Evans' hobby was golf, and a fortnight before his death he completed two rounds on the links at Aberdovey, perhaps too much for a man of 70 . He had, only a few months before the end, retired to his country cottage by the sea to nurse his wife who had become an invalid, and to be with her as much as possible. As things turned out his retirement from an arduous practice was short, and our sympathies go out to Mrs. Jameson Evans and her two sons, one of whom, Philip, carries on his father's work as Assistant Surgeon to the Birmingham Eye Hospital.

We have also received the following appreciation from an old friend who wishes to remain anonymous.

To his many friends, professional and private, the passing of J. Jameson Evans is a grievous blow. The character of his per. sonality united a wide and simple human sympathy with a helpfulness that created an abiding impression on all who came in contact with him.

He made numerous and valuable contributions to ophthalmic literature and but for the war, he would have opened the discussion at the postponed Oxford Ophthalmological Congress of 1940, on the subject of the prevention of operative complications following extraction of cataract.

As a lecturer Jameson Evans was a master of concise and pregnant exposition and his wide range of culture, his quickness of mind and his abundant human vitality and wit made him a teacher of unusual power. At the same time he was never happier than at his home and on the links at Aberdovey. The deepest sympathy of all his friends is extended to his widow and two sons. 